\title{
ASSESMENT OF PRIMARY STABILITY AND BONE DENSITY OF MAXILLARY IMPLANT OVERDENTURE FOLLOWING OSSEO DENSIFICATION CONCEPT
}

\author{
Khaled Abdelwahab*, Alaa A. Nawwar** and Nada Sherin El Khourazaty**
}

\begin{abstract}
Objectives: To evaluate the effect of osseodensification concept using Densah bur on implant primary stability and peri-implant bone density in maxillary implant overdenture.

Materials and Methods: Ten completely edentulous patients were selected and two implants were inserted in the maxilla for each patient in a split mouth study design; one implant with the conventional drilling system and one implant with the Densah bur drilling system. Implant primary stability was assessed using ostell device at the time of implant placement and at prosthetic rehabilitation phase $(4 \mathrm{~m})$. Bone density around the implants was measured using CBCT at 3,6,12 months intervals.
\end{abstract}

Results: Significant difference was found regarding Osstell values as well as bone density measurements between both groups throughout the study period

Conclusions: Within the limitation of this study, Densah drilling burs that adopt the osseodensification concept. Have displayed more primary stability compared to the conventional drilling protocol in terms of primary stability as well as bone density for delayed loaded implants used to retain and support maxillary overdentures.

KEYWORDS: Implants, primary stability, osseodensification, bone density, overdenture.

\section{INTRODUCTION}

The evidenced implant success over the years made it the treatment of choice for replacing lost teeth in its different forms. (Guillaume, 2016) (Sakka et al., 2012) Successful dental implant placement requires sufficient amount of bone thick- ness covering the implant so that primary stability is achieved, which is an important requirement for long term success of the implant.(Monje et al., 2019) (Marquezan et al., 2012) From the factors affecting implant primary stability are bone density, surgical protocol, and implant design. Ample bone thickness covering the implant is not often found as

\footnotetext{
* Associate Professor, Department of Prosthodontics, Cairo University, New Giza University

** Lecturer of Oral and Maxillofacial Radiology, Faculty of Dentistry, Cairo University

** Professor, Associate professor of Prosthodontics, Faculty of Dentistry Cairo University
} 
bone resorption after extraction can reach approximately $50 \%$ of the original bone width in under a year. Also, in areas of low bone density as in the maxilla; maintaining sufficient bone bulk and density is essential to achieve necessary bone to implant contact for obtaining a biomechanically stable implant.(Alghamdi \& Jansen, 2020) (Turkyilmaz et al., 2008) (Trisi et al., 2011)

Horizontal bone augmentation for implant placement is often necessary in deficient alveolar ridges.(Aghaloo et al., 2017)(Elnayef et al., 2017) Various methods have been demonstrated in the literature to treat horizontal defects such as guided bone regeneration (GBR)(Urban et al., 2013), autogenous block grafts(Monje et al.,2015), alveolar distraction osteogenesis(Funaki et al., 2009), ridge splitting(Simion et al., 1992), ridge expansion procedures(Santagata et al., 2011) developed and are used to augment and treat bone volume defects.

Ridge expansion, utilizing motorized rotary expanders, has been suggested as an alternative technique to expand bone by displacing it.(Pai et al., 2018) Osseodensification is a non-excavating (no cutting) implant site preparation technique. It creates a densified layer of surrounding bone through compaction autografting while simultaneously plastically expanding the bony ridge at the same time. (Mullings et al., 2021) The autografting occurs along the entire length of the osteotomy through a hydrodynamic process with the use of irrigation. The result is a consistently cylindrical and densified osteotomy. (Lahens et al., 2016; Podaropoulos, 2017; Tretto et al., 2019; Trisi et al., 2016)

It is well known that the longevity of any implant prosthesis depends on successful osseointegration and implant stability.(T.-J. Oh et al., 2002; Sakka et al., 2012) (CARMO FILHO et al., 2018)Consistent osteotomies and densification are important to implant primary stability and loading.(Lahens et al., 2016) One technique for measuring implant stability is resonance frequency analysis aiming to pro- vide an objective measure of implant stability and Osseointegration, which is noninvasive and does not damage the implant tissue interface. (H et al., 2020) (Sennerby \& Meredith, 2008) The resonance frequency analysis technique has been extensively used in experimental and clinical research for the last two decades. Also Cone Beam Computed Tomography (CBCT) has been widely used for the follow-up of dental implants and is considered one of the tools for assessing bone changes and implant success. CBCT scanners provide adequate image quality for dento-maxillofacial examinations while delivering considerably smaller effective doses to the patient. when compared to CT scanners (de Elío Oliveros et al., 2020) (Loubele et al., 2008) (de Elío Oliveros et al., 2020) (Suomalainen et al., 2009)

Locator attachment is one system that has been widely used by clinicians, particularly, for twoimplant-supported situations (Nischal et al., 2020) and has showed comparable results regarding crestal bone changes and patient satisfaction. (Mumcu \& Dereci, 2019).

This study was conducted to investigate the effect of Osseodensification using the Densah bur drilling system on the primary stability and bone changes in maxillary implants when compared with conventional drilling system in implants used to retain an overdenture.

\section{MATERIALS AND METHODS}

Ten completely edentulous male patients were selected from the outpatient clinic of the Prosthodontics Department; Faculty of Oral and Dental Medicine, Cairo University. The patients' ages ranged from 50-65 years old and were systemically free from any disease that may interfere with dental implant placement and/ or osseointegration. Patients were selected to have adequate bone height and width for implant placement as preliminary detected from cone beam computed tomography $\mathrm{CBCT}$ and was confirmed 
later during pilot drilling, as well as sufficient inter arch space for overdenture construction with normal maxillo-mandibular relation. Only cooperative patients capable of following instructions and those with proper neuromuscular coordination were included in the study. Thorough patient history, clinical examination and radiographic assessment were carefully done for verification of the selection criteria. The patients were familiarized with the nature of the study and requested to sign consent forms before beginning the study.

Study casts were produced from primary alginate impressions for the upper and lower arches of each patient. Acrylic resin special trays were constructed on the diagnostic casts and used in recording the final impressions using zinc oxide and eugenol impression material. Master casts were obtained and occlusion blocks were constructed for jaw relation registration, followed by mounting of the master casts on the articulator. Setting-up of cross-linked acrylic resin teeth was done following the lingualized occlusion concept. Try-in was performed, after which the dentures were processed following conventional techniques using high impact acrylic resin.

At the delivery appointment, final occlusal adjustments and refinements were done and the dentures were delivered to the patients 6 weeks before the surgical appointment to achieve sufficient patient adaptation to their new dentures. The finished upper denture was duplicated for each patient and processed in clear acrylic resin in order to construct a surgical guide template to facilitate implant placement during surgery at canine or first premolar area.

After flap reflection, for both osteotomy sites implant manufacturer's pilot drill was used to perform a standard osteotomy of $10 \mathrm{~mm}$ depth. Then the sequential use of densah* bur (Fig 1) $2.0 \mathrm{~mm}$ pilot, $2.8 \mathrm{~mm}$, and $3.4 \mathrm{~mm}$ multi-fluted tapered burs in a counterclockwise direction under copious irrigation was done in one osteotomy site while drilling the other site using the conventional sequential drilling system. Two $3.6 \mathrm{~mm}$ in diameter, $10 \mathrm{~mm}$ in length implants** $^{* *}$ were placed using the torque wrench in each osteotomy site. Smart pegs were mounted for each implant for Primary stability measurement using Ostell device ${ }^{* * *}$. Healing collars were placed followed by suturing around the implants.

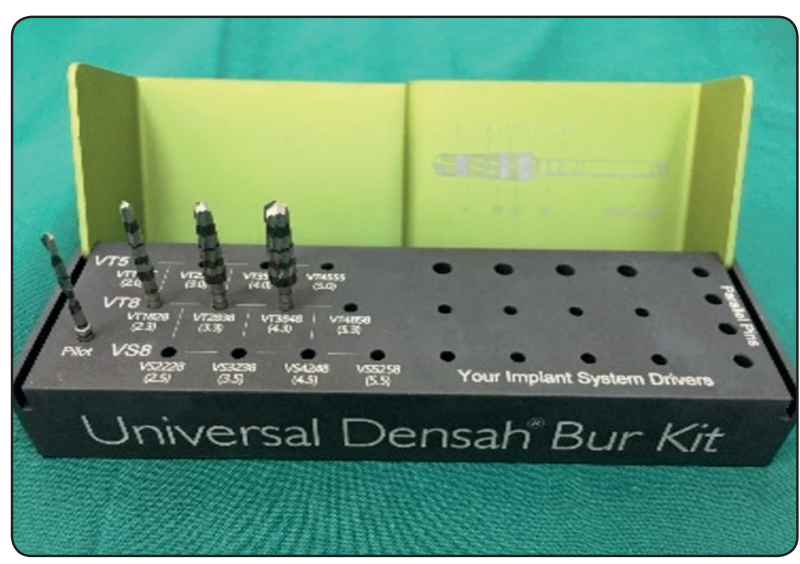

Fig. (1): Densah burs kit

All patients were instructed to administer $2 \mathrm{gm} /$ day amoxicillin-clavulanate and $50 \mathrm{mg} / 8$ hours non-steroidal anti-inflammatory analgesics for 5 days postoperatively. Postoperative instructions including a soft diet and appropriate oral hygiene measures with $0.2 \%$ chlorhexidine mouth rinse.

The dentures were picked up 4 months after surgery following delayed loading protocol. Healing collars were unscrewed and replaced by smart peg for the primary stability measurement and finally replaced by locator attachments****. (Fig 2) Holes corresponding to the attachments were drilled in the fitting surface of the denture to allow seating

\footnotetext{
* Vesrsah LLC

** Legacy II Implants, Implant Direct TM LLC Spectra-System Dental Implants, 27030 Malibu Hills, USA

*** Osstell ,USA

**** Locator attachments, Zest Anchor, USA
} 
of the denture without any interference with the housings, as proved by absence of rocking, pressure indicating paste and proper occlusion. Acrylic resin pick-up material was injected in the denture at the corresponding holes and inserted over the locator attachments. The resin was left to polymerize while the patient was closing in centric jaw relation with gentle pressure. The overdenture was removed, trimmed and polished. The dentures were delivered and oral hygiene instructions were given to the patients.

Implant primary stability measurements for each implant was done at the time of surgery and 4 months (delivery of the prosthesis). Implant stability was assessed using the Osstell that was used according to the manufacturer's instructions and held perpendicular to the provided implant smart peg. Osstell values (ISQ) were obtained for the buccal, lingual, mesial and distal surfaces of each implant. Three measurements were made for each surface and the mean was obtained for statistical analysis.

Using Cone Beam Computed Tomography (CBCT). The patients were scanned before the implant insertion for planning purposes, the scan was repeated with the same protocol after 3, 6 and 12 months of implant insertion.
CBCT images were acquired* then a scout view was obtained and adjustments were made to ensure that all radiographs were correctly aligned in the scanner according to adjustment light beam before acquisition and operating at the following protocol for all the scans of the study; parameters $90 \mathrm{kVp}$ milliampere $10.07 \mathrm{mAs}$ and voxel size $0.20 \mathrm{~mm}$.

After acquisition, data was exported and transferred in DICOM format for further analysis. For density measurement, OnDemand software ${ }^{* *}$ was utilized to superimpose the 3-month scan, 6-month scan and 12-month scan, hence guaranteeing measuring density at the exact cut. Fusion module was used to superimpose different scans where automatic registration was performed by the software. Superimposition sequence was repeated for each patient individually.

After fusion, the scans were reconstructed at the same layer and orientation. For density measurement around one implant, both coronal and sagittal lines were moved to intersect at the center of the implant, parallel to its long axis as well, then the reconstructed planes will represent the mesiodistal and bucco-lingual perspectives of the implant, at which recording of bone density using density measurement tool was used (Fig 3). The same

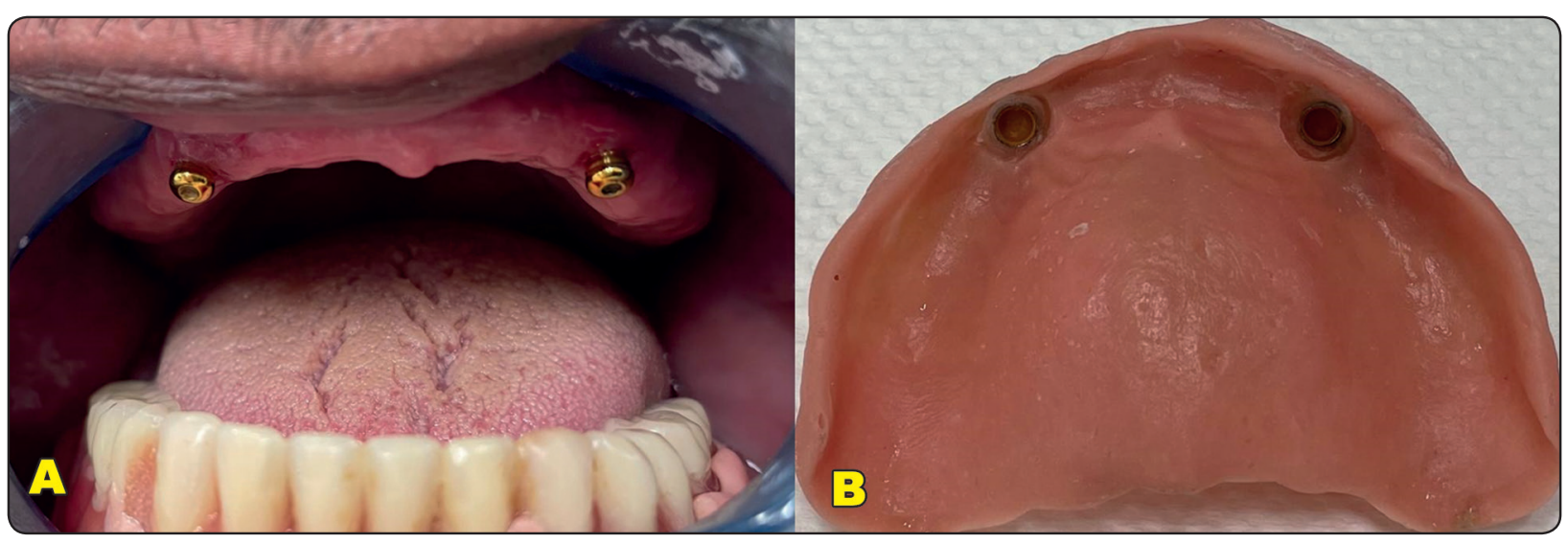

Fig. (2) A:Locators attachment in place.

B: Female parts picked up in the denture

\footnotetext{
* Planmeca Mid scanner (Planmeca, Finland)

** OnDemand software 3D Dental software (Cyber med, South Korea)
} 


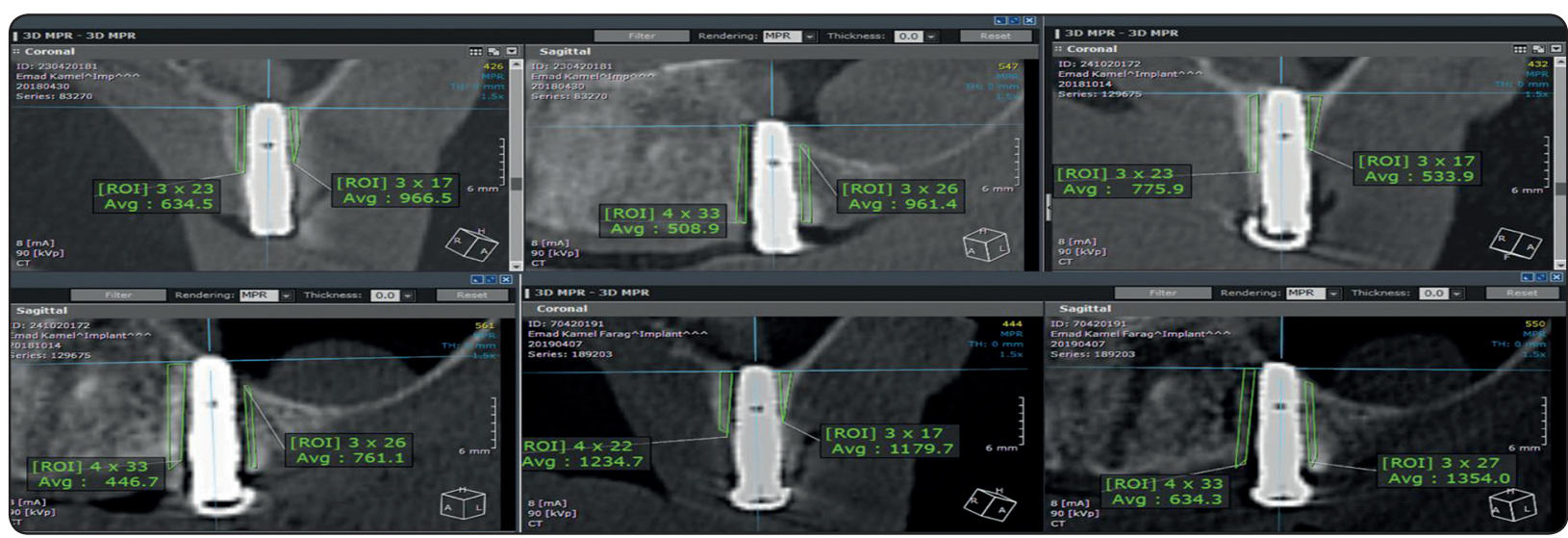

Fig. (3) : Density measurement

surface area was chosen, at both sides, and at both scans as well. For measuring bone density around the other implant, reference lines were moved to the center of the corresponding implants, then the same steps were repeated. The results were then recorded and tabulated for statistics.

\section{RESULTS}

The mean and standard deviation values were calculated for each group in each test. Data was explored for normality using Kolmogorov-Smirnov and Shapiro-Wilk tests, data showed parametric (normal) distribution.

Paired sample t-test was used to compare between two groups in related samples.

The significance level was set at $\mathrm{P} \leq 0.05$. Statistical analysis was performed with $\mathrm{IBM}^{\circledR}$ SPSS $®$ Statistics Version 20 for Windows.

\section{Primary stability}

There was a statistically significant difference in implant primary stability between the conventional group and densah bur group both at the base line (implant installation) and at 4-month interval, in which the densah bur group showed higher ISQ values of primary stability with a mean value of $(67.67 \pm 5.87)$ at implant installation and (68.92 \pm 2.87) after 3 months.
TABLE (1): The mean, standard deviation (SD) values of Primary stability of different groups

\begin{tabular}{|c|c|c|c|c|c|}
\hline \multirow{2}{*}{ Variables } & \multicolumn{4}{|c|}{ Primary stability } \\
\cline { 2 - 5 } & \multicolumn{4}{|c|}{ Conventional } & \multicolumn{2}{|c|}{ Densah bur } & \multirow{2}{*}{ p-value } \\
\cline { 2 - 5 } & Mean & SD & Mean & SD & \\
\hline Baseline & 60.67 & 8.95 & 67.67 & 5.87 & \multirow{0}{*}{$\mathbf{0 . 0 3 4 *}$} \\
\hline 4 m & 64.42 & 5.26 & 68.92 & 2.87 & \multirow{2}{*}{$\mathbf{0 . 0 1 6 *}$} \\
\hline p-value & \multicolumn{2}{|c|}{$\mathbf{0 . 2 6 2 n s}$} & $\mathbf{0 . 5 7 9 n s}$ & \\
\hline
\end{tabular}

*; significant $(p<0.05) \quad n s ;$ non-significant $(p>0.05)$

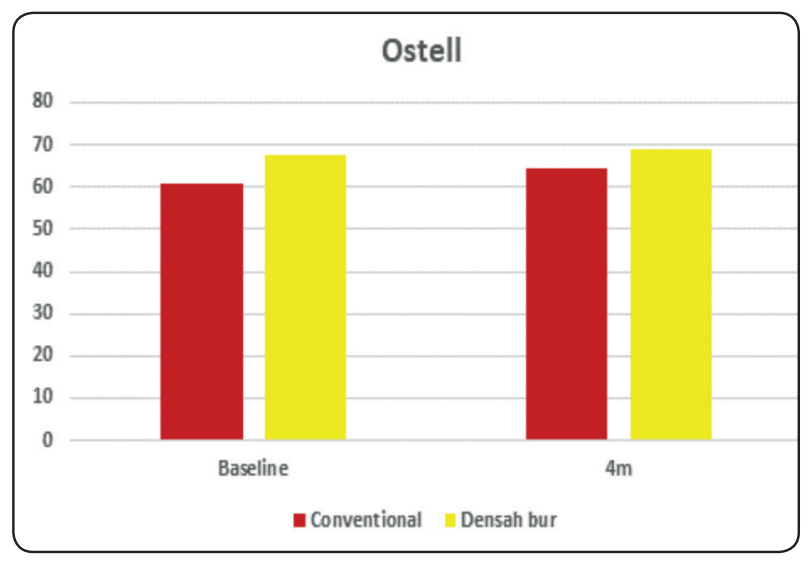

Fig. (4): Bar chart representing Primary stability for different groups 


\section{Bone density}

There was a statistically significant difference between the conventional and the densah bur group in which the densah bur showed higher mean values in all intervals $(3,6,12$ months).

TABLE (2): The mean, standard deviation (SD) values of BONE DENSITY of different groups

\begin{tabular}{|c|c|c|c|c|c|}
\hline \multirow{3}{*}{ Variable } & \multicolumn{4}{|c|}{ BONE DENSITY } & \multirow{3}{*}{ p-value } \\
\hline & \multicolumn{2}{|c|}{ Conventional } & \multicolumn{2}{|c|}{ Densah bur } & \\
\hline & Mean & SD & Mean & SD & \\
\hline $3 m$ & 407.33 & 55.01 & 511.22 & 96.31 & 0.013* \\
\hline $6 \mathrm{~m}$ & 410.33 & 55.01 & 491.89 & 55.17 & $0.172 n s$ \\
\hline $12 \mathrm{~m}$ & 739.33 & 30.74 & 804.78 & 43.67 & $0.002 *$ \\
\hline p-value & \multicolumn{2}{|c|}{$<0.001$} & \multicolumn{2}{|c|}{$<0.001 *$} & \\
\hline
\end{tabular}

*; significant $(p<0.05) \quad n s ;$ non-significant $(p>0.05)$

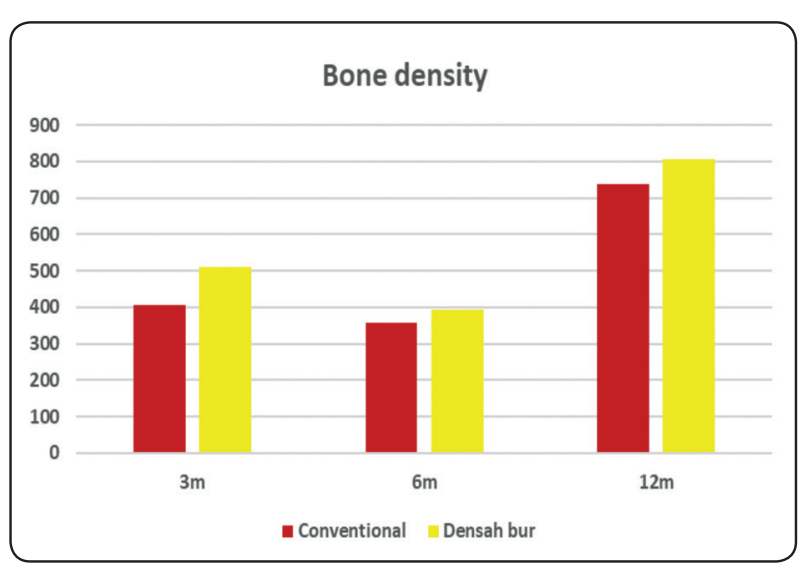

Fig. (5): Bar chart representing BONE DENSITY for different groups

\section{DISCUSSION}

The aim of this study was to inspect the impact of the osseodensification concept on implant primary stability a well as its effect on the bone density of the implant's surrounding bone.
Implant stability and bone density are considered from the important criteria for successful osseointegration. (J.-S. Oh et al., 2009) (de Elío Oliveros et al., 2020) The clinical perception of primary implant stability is usually based on the cutting resistance, bone quality as well as the surgical fit achieved by the implant during drilling and insertion.

It is claimed that Osseodensification utilizing the Densah Bur technology produces stronger osteotomy for any implant as it preserves the bone to enhance the host osteotomy. This allows for clinical versatility, which may facilitate enhanced implant stability and efficient expansion of any ridge in either jaw. (Koutouzis et al., 2019) (Mullings et al., 2021).

Authors in this study preferred to use the delayed loading protocol as the rates of implant loss following immediate loading in overdentures is higher in comparison to delayed loading.(Arafat \& A Elbaz, 2019) (Liu et al., 2021) Resonance frequency analysis (RFA) offers a noninvasive clinical measurement of stability and osseointegration of implants; it is considered a useful tool to establish the implant loading time. The RFA values are represented by a quantitative unit called the Implant Stability Quotient (ISQ) on a scale from 1 to 100 . (Mokhtari et al., 2010) (H et al., 2020) Radiographic evaluation of bone density using the CBCT proved to be accurate as it is relatively insensitive to the interference caused by dental artefacts placed adjacent to edentulous bone sites. (Monje et al., 2015) (Marquezan et al., 2012)

The results of the current study showed a significant difference in implant primary stability between the conventional and densah bur at both intervals with higher ISQ mean values with the densah bur than that with the conventional which can be explained by the fact that the densah bur osseous densification technique increases primary stability and the percentage of bone at the implant surface by creating a crust of increased bone mineral density around the osteotomy site. Moreover it preserves bone bulk in two ways: compaction of cancellous 
bone due to viscoelastic and plastic deformation, and compaction autografting of bone particles along the length and at the apex of the osteotomy. (Huwais $\&$ Meyer, 2017). These results were in accordance with the study performed by (Arafat \& A Elbaz, 2019) where the authors used the Densah burs for ossedensification during sinus floor elevation in atrophic maxilla.

Moreover, a significant difference regarding bone density was found as well between the conventional and the densah bur at all intervals (3,6,12months) with higher mean values with the densah bur which may be due to that drilling with densah bur resulted in undersized osteotomy compared to that with the conventional drills. It may have also resulted in an improved bone density and increase in percentage of bone volume and bone-toimplant contact as previously explained in another study by (Pai et al., 2018)

\section{CONCLUSION}

Within the limitation of this study Densah drilling burs which adopt the osseodensification concept have displayed better results compared to the conventional drilling protocol in terms of primary stability as well as bone density. For delayed loaded implants used to retain and support a maxillary overdentures. More studies are needed to assess the effect of this drilling protocol in cases with immediate loading protocol.

\section{REFERENCES}

- Aghaloo, T., Misch, C., Lin, G.-H., Iacono, V., \& Wang, H.-L. (2017). Bone Augmentation of the Edentulous Maxilla for Implant Placement: A Systematic Review. The International Journal of Oral \& Maxillofacial Implants, 31, s19-s30. https://doi.org/10.11607/jomi.16suppl.g1

- $\quad$ Alghamdi, H. S., \& Jansen, J. A. (2020). The development and future of dental implants. Dental Materials Journal, 39(2), 167-172. https://doi.org/10.4012/dmj.2019-140

- Arafat, S., \& A Elbaz, M. (2019). Clinical and radiographic evaluation of osseodensification versus osteotome for sinus floor elevation in partially atrophic maxilla:
A prospective long term study. Egyptian Dental Journal, 65(1), 189-195. https://doi.org/10.21608/edj.2015.71261

- Carmo Filho, L. C. DO, Marcello-Machado, R. M., Castilhos, E. D. De, Del Bel Cury, A. A., \& FAOT, F. (2018). Can implant surfaces affect implant stability during osseointegration? A randomized clinical trial. Brazilian Oral Research, 32, e110. https://doi.org/10.1590/18073107bor-2018.vol32.0110

- de Elío Oliveros, J., del Canto Díaz, A., del Canto Díaz, M., Orea, C. J., del Canto Pingarrón, M., \& Calvo, J. S. (2020). Alveolar Bone Density and Width Affect Primary Implant Stability. Journal of Oral Implantology, 46(4), 389-395. https://doi.org/10.1563/aaid-joi-D-19-00028

- $\quad$ Elnayef, B., Monje, A., Albiol, G., Galindo-Moreno, P., Wang, H.-L., \& Hernández-Alfaro, F. (2017). Vertical Ridge Augmentation in the Atrophic Mandible: A Systematic Review and Meta-Analysis. The International Journal of Oral \& Maxillofacial Implants, 32(2), 291-312. https:// doi.org/10.11607/jomi.4861

- $\quad$ Funaki, K., Takahashi, T., \& Yamauchi, K. (2009). Horizontal alveolar ridge augmentation using distraction osteogenesis: comparison with a bone-splitting method in a dog model. Oral Surgery, Oral Medicine, Oral Pathology, Oral Radiology, and Endodontology, 107(3), 350-358. https:// doi.org/10.1016/j.tripleo.2008.10.005

- Guillaume, B. (2016). Dental implants: A review. Morphologie, 100(331), 189-198. https://doi.org/10.1016/j. morpho.2016.02.002

- H, H., G, W., \& E, H. (2020). The clinical significance of implant stability quotient (ISQ) measurements: A literature review. Journal of Oral Biology and Craniofacial Research, 10(4), 629-638. https://doi.org/10.1016/j.jobcr.2020.07.004

- Huwais, S., \& Meyer, E. (2017). A Novel Osseous Densification Approach in Implant Osteotomy Preparation to Increase Biomechanical Primary Stability, Bone Mineral Density, and Bone-to-Implant Contact. The International Journal of Oral \& Maxillofacial Implants, 32(1), 27-36. https://doi.org/10.11607/jomi.4817

- $\quad$ Koutouzis, T., Huwais, S., Hasan, F., Trahan, W., Waldrop, T., \& Neiva, R. (2019). Alveolar Ridge Expansion by Osseodensification-Mediated Plastic Deformation and Compaction Autografting. Implant Dentistry, 28(4), 349-355. https://doi.org/10.1097/ID.0000000000000898

- $\quad$ Lahens, B., Neiva, R., Tovar, N., Alifarag, A. M., Jimbo, R., Bonfante, E. A., Bowers, M. M., Cuppini, M., Freitas, 
H., Witek, L., \& Coelho, P. G. (2016). Biomechanical and histologic basis of osseodensification drilling for endosteal implant placement in low density bone. An experimental study in sheep. Journal of the Mechanical Behavior of Biomedical Materials, 63, 56-65. https://doi.org/10.1016/j. jmbbm.2016.06.007

- $\quad$ Liu, W., Cai, H., Zhang, J., Wang, J., \& Sui, L. (2021). Effects of immediate and delayed loading protocols on marginal bone loss around implants in unsplinted mandibular implant-retained overdentures: a systematic review and meta-analysis. BMC Oral Health, 21(1), 122. https://doi. org/10.1186/s 12903-021-01486-3

- Loubele, M., Maes, F., Jacobs, R., van Steenberghe, D., White, S. C., \& Suetens, P. (2008). Comparative study of image quality for MSCT and CBCT scanners for dentomaxillofacial radiology applications. Radiation Protection Dosimetry, 129(1-3), 222-226. https://doi.org/10.1093/ $\mathrm{rpd} / \mathrm{ncn} 154$

- Marquezan, M., Osório, A., Sant'Anna, E., Souza, M. M., \& Maia, L. (2012). Does bone mineral density influence the primary stability of dental implants? A systematic review. Clinical Oral Implants Research, 23(7), 767-774. https://doi.org/10.1111/j.1600-0501.2011.02228.x

- Mokhtari, M. R., Radvar, M., Sargolzaie, N., \& Moeintagavi, A. (2010). Resonance Frequency Analysis of Clinical Stability of Astra Tech and ITI Implant Systems. Journal Of Periodontology.

- Monje, A., Monje, F., Hernández-Alfaro, F., GonzalezGarcía, R., Suárez-López del Amo, F., Galindo-Moreno, P., Montanero-Fernández, J., \& Wang, H.L. (2015). Horizontal Bone Augmentation Using Autogenous Block Grafts and Particulate Xenograft in the Severe Atrophic Maxillary Anterior Ridges: A Cone-Beam Computerized Tomography Case Series. Journal of Oral Implantology, 41(S1), 366371. https://doi.org/10.1563/AAID-JOI-D-13-00219

- Monje, A., Ravidà, A., Wang, H.-L., Helms, J. A., \& Brunski, J. B. (2019). Relationship Between Primary/Mechanical and Secondary/Biological Implant Stability. The International Journal of Oral \& Maxillofacial Implants, 34, s7-s23. https://doi.org/10.11607/jomi.19suppl.g1

- Mullings, O., Tovar, N., de Bortoli, J., Parra, M., Torroni, A., Coelho, P., \& Witek, L. (2021). Osseodensification Versus Subtractive Drilling Techniques in Bone Healing and Implant Osseointegration: Ex Vivo Histomorphologic/ Histomorphometric Analysis in a Low-Density Bone
Ovine Model. The International Journal of Oral \& Maxillofacial Implants, 36(5), 903-909. https://doi.org/10.11607/ jomi.8828

- $\quad$ Mumcu, E., \& Dereci, Ö. (2019). Assessment of the Effect of Clinical Independent Risk Factors on Marginal Bone Loss in 2-Implant-Supported Locator-Retained Mandibular Overdentures. The Journal of Oral Implantology, 45(3), 207-212. https://doi.org/10.1563/aaid-joi-D-18-00193

- Nischal, K., Mishra, S. K., \& Chowdhary, R. (2020). Crestal Bone Changes and Patient Satisfaction with Single Implant-Retained Mandibular Overdentures with Dalla Bona and Locator Attachments with Immediate Loading Protocols. A Randomized Controlled Clinical Study. Journal of Prosthodontics, 29(9), 756-765. https://doi. org/10.1111/jopr.13230

- $\quad$ Oh, J.-S., Kim, S.-G., Lim, S.-C., \& Ong, J. L. (2009). A comparative study of two noninvasive techniques to evaluate implant stability: Periotest and Osstell Mentor. Oral Surgery, Oral Medicine, Oral Pathology, Oral Radiology, and Endodontics, 107(4), 513-518. https://doi.org/S10792104(08)00627-6 [pii] \r10.1016/j.tripleo.2008.08.026

- Oh, T.-J., Yoon, J., Misch, C. E., \& Wang, H.-L. (2002). The causes of early implant bone loss: myth or science? The Journal of Periodontology, 73(3), 322-333. https:// doi.org/10.1902/jop.2002.73.3.322

- $\quad$ Pai, U., Rodrigues, S., Talreja, K., \& Mundathaje, M. (2018). Osseodensification - A novel approach in implant dentistry. The Journal of Indian Prosthodontic Society, 18(3), 196. https://doi.org/10.4103/jips.jips_292_17

- Podaropoulos, L. (2017). Increasing the Stability of Dental Implants: the Concept of Osseodensification. Balkan Journal of Dental Medicine, 21(3), 133-140. https://doi. org/10.1515/bjdm-2017-0023

- $\quad$ Sakka, S., Baroudi, K., \& Nassani, M. Z. (2012). Factors associated with early and late failure of dental implants. Journal of Investigative and Clinical Dentistry, 3(4), 258261. https://doi.org/10.1111/j.2041-1626.2012.00162.x

- $\quad$ Santagata, M., Guariniello, L., \& Tartaro, G. (2011). A Modified Edentulous Ridge Expansion Technique for Immediate Placement of Implants: A Case Report. Journal of Oral Implantology, 37(sp1), 114-119. https://doi. org/10.1563/AAID-JOI-D-10-00035.1

- Sennerby, L., \& Meredith, N. (2008). Implant stability measurements using resonance frequency analysis: biological and biomechanical aspects and clinical im- 
plications. Periodontology 2000, 47, 51-66. https://doi. org/10.1111/j.1600-0757.2008.00267.x

- $\quad$ Simion, M., Baldoni, M., \& Zaffe, D. (1992). Jawbone enlargement using immediate implant placement associated with a split-crest technique and guided tissue regeneration. The International Journal of Periodontics \& Restorative Dentistry, 12(6), 462-473. http://www.ncbi.nlm.nih.gov/ pubmed/1298734

- $\quad$ Suomalainen, A., Kiljunen, T., Käser, Y., Peltola, J., \& Kortesniemi, M. (2009). Dosimetry and image quality of four dental cone beam computed tomography scanners compared with multislice computed tomography scanners. Dento Maxillo Facial Radiology, 38(6), 367-378. https:// doi.org/10.1259/dmfr/15779208

- $\quad$ Tretto, P. H. W., Fabris, V., Cericato, G. O., Sarkis-Onofre, R., \& Bacchi, A. (2019). Does the instrument used for the implant site preparation influence the bone-implant interface? A systematic review of clinical and animal studies. International Journal of Oral and Maxillofacial Surgery, 48(1), 97-107. https://doi.org/10.1016/j.ijom.2018.04.005

- $\quad$ Trisi, P., Berardini, M., Falco, A., \& Podaliri Vulpiani, M. (2016). New Osseodensification Implant Site Preparation
Method to Increase Bone Density in Low-Density Bone: In Vivo Evaluation in Sheep. Implant Dentistry, 25(1), 2431. https://doi.org/10.1097/ID.0000000000000358

- $\quad$ Trisi, P., De Benedittis, S., Perfetti, G., \& Berardi, D. (2011). Primary stability, insertion torque and bone density of cylindric implant ad modum Branemark: Is there a relationship? An in vitro study. Clinical Oral Implants Research, 22(5), 567-570. https://doi.org/10.1111/j.16000501.2010.02036.x

- Turkyilmaz, I., Aksoy, U., \& McGlumphy, E. A. (2008). Two alternative surgical techniques for enhancing primary implant stability in the posterior maxilla: a clinical study including bone density, insertion torque, and resonance frequency analysis data. Clinical Implant Dentistry and Related Research, 10(4), 231-237. https://doi.org/10.1111/ j.1708-8208.2008.00084.x

- Urban, I. A., Nagursky, H., Lozada, J. L., \& Nagy, K. (2013). Horizontal Ridge Augmentation with a Collagen Membrane and a Combination of Particulated Autogenous Bone and Anorganic Bovine Bone-Derived Mineral: A Prospective Case Series in 25 Patients. The International Journal of Periodontics and Restorative Dentistry, 33(3), 299-307. https://doi.org/10.11607/prd.1407 